\title{
Technical Notes Botanical components of annual Mediterranean grassland as determined by point-intercept and clipping methods
}

\author{
A. GLATZLE, A. MECHEL, AND M.E. VAZ LOURENCO
}

Authors with the Centre for Agriculture in the Tropics and Subtropics, University of Hohenheim (480), P.O. Box 700562, D-7000 Stuttgart-70, Germany; and Departamento de Fitotecnia, Universidade de Evora, Apartado 94, 7001 Evora-Codex, Portugal, respectively. Currently A. Glatzle's present address is Estación Experimental Chaco Central, Casilla de Correo 1859, Asunción, Paraguay.

\begin{abstract}
Three methods for determining proportions of botanical components, i.e., grasses, legumes, and forbs (nonleguminous dicots), of continuously grazed Mediterranean pastures were compared. Percentage contribution to dry matter yield was determined by sample clipping and separating into botanical components. Both percentage of sward and specific contribution were determined by the point-intercept method. These were defined by the relative contribution of 1 botanical component to the total number of counted intercepts between 200 pins inserted vertically into the sward and all botanical components. For specific contribution only the number of pins contacted by the various botanical components were considered, whereas for percentage of sward even multiple contacts between a pin and plant parts of a particular botanical component were taken into account.

Percentage contribution was highly significantly correlated with percentage of sward $(R=0.92)$ and specific contribution $(R=0.93)$ running the analyses across all botanical components, although there was a significant trend to underestimate forbs and overestimate legumes by the point-intercept methods. It is concluded, however, that for most practical purposes determination of specific contribution, the least laborious method, should give satisfactory estimates of percentage contribution.
\end{abstract}

Key Words: botanical composition, percentage of sward, specific contribution, percentage contribution, sward measurement

The point-intercept method has been widely used as a tool for vegetation studies, especially in pastures and rangeland. Originally described as the point-quadrat method (Levy and Madden 1933, Goodall 1952, Goodall 1953) using a string grid or a frame with steel pins to determine whether or not the vertical projection of a point intercepts with a plant shoot part, the method has since been subjected to several modifications (e.g., Heady and Rader 1958, Daget et Poissonet 1971, Taha et al. 1985).

The interpretation of the results depends upon whether only a list of the species touched by each pin is recorded or the number of contacts with each species is counted. Provided the diameter of the pins used is negligibly small, the mean number of points per 100 examined, at which contact is made with 1 particular species, corresponds to the percentage of ground covered by that species. This was referred to as percentage cover by Levy and Madden (1933).

Percentage of sward was defined by Levy and Madden (1933) as, comparing the number of pin-intercepts with 1 species to the number of intercepts with all species. This means, the total number of contacts with the aboveground plant parts of a species was recorded. In contrast, specific contribution was defined by Daget et Poissonet (1971) as the number of species hit by each pin, irrespective of eventually occurring multiple contacts.

Percentage cover is influenced by the diameter of the pins used and tends to be overestimated (since diameter never is zero). The percentage of sward and specific contribution are generally considered independent of needle size. Mueller-Dombois and Ellenberg (1974) claimed that cover repetition can be correlated to biomass, provided correlations are worked out empirically for each vegetation type analysed.

The objective of this study was to find out to what extent percentage contribution to dry matter yield, which is laborious to determine, is correlated with percentage of sward and specific contribution.

\section{Materials and Methods}

The study was carried out at Mitra Farm, an experimental station of Evora University, in the Alentejo region of Portugal. The average annual rainfall is $764 \mathrm{~mm}$ (winter incidence). Shallow, sandy, acidic soils prevail. The landscape is a typical, slightly undulating "motado"-area (Marañon 1988) characterized by scattered oak trees (Quercus ilex L. and Quercus suber L.) in seminatural grasslands. Traditional land-use is sylvo-pastoral.

Three continuously grazed pasture plots of 2 ha each were chosen. Two of them (plots B and C) had been sown in the past (1986), 1 with Trifolium subterraneum L. and 1 with Ornithopus compressus L. respectively. The species sown, however, contributed less than $5 \%$ of dry matter to the sward. One pasture had never been sown (plot A). Stocking densities were 6.0, 5.0, and 6.5 Merino sheep ( $50 \mathrm{~kg}$ liveweight) per hectare on plots $\mathrm{A}, \mathrm{B}$, and $\mathrm{C}$ respectively. The dominant species on all pastures were Vulpia geniculata (L.) Link, Bromus mollis L. and B. rigidus Roth (grasses), Ornithopus compressus L., Trifolium subterraneum L. and other clovers such as $T$. fragiferum L., $T$. stellatum L., and $T$. campestre Schreb. (legumes), as well as Tolpis barbata (L.) Gaertn., Rumex bucephalophorus L., Erodium moschatum (L.) L'Hérit., Coleostephus myconis Dur, and Leontodon hispidus (Del) Boiss. (forbs defined as nonleguminous dicotyledons).

Between January and May 1988 (main growing season) the development of the botanical components (grasses, legumes, and forbs) on the 3 pastures was observed monthly by 3 different methods. During this time the average sward height never exceeded $8 \mathrm{~cm}$. Standing biomass increased from 440,537, and $704 \mathrm{~kg}$ dry 
matter ha ${ }^{-1}$ in January to 781,808 , and $832 \mathrm{~kg}$ dry matter ha $^{-1}$ in April for pastures A, B, and C, respectively.

At the middle of every month, percentage contribution to dry matter yield, percentage of sward, and specific contribution of botanical components were measured.

For determination of percentage contribution, a clipping frame of $0.1 \mathrm{~m}^{2}(0.4 \mathrm{~m}$ by $0.25 \mathrm{~m})$ was randomly tossed 30 times over each pasture (Frame 1981). The biomass harvested within the frames was separated into the above-mentioned botanical components, oven-dried and weighed, and their proportion of total dry matter was calculated.

Percentage of sward and specific contribution were determined using a modified point-intercept method similar to that described ، by Daget et Poissonet (1971) and Glatzle (1990). Meter tapes were stretched along both diagonals of each pasture and, at equal distances along each diagonal, 100 steel pins of $2 \mathrm{~mm}$ diameter were inserted vertically into the soil. All contacts of pins with the pasture crop were noted separately for grasses, legumes, and forbs. Percentage of sward (PS) was calculated by formula (1), and specific contribution (SC) by formula (2).

$$
\begin{aligned}
& \mathrm{PS}=\frac{\text { number of all pin-contacts with plant parts of } 1 \mathrm{BC}}{\text { number of all pin-contacts with plant parts of all BCs }} * 100 \\
& \mathrm{SC}=\frac{\text { number of pins contacted by } 1 \mathrm{BC}}{\text { sum of number of pins contacted by each of the BCs }} * 100
\end{aligned}
$$

with $\mathrm{BC}=$ botanical component

Statistical evaluation was a three-factorial analysis of variance where the factors methods applied and dates of observation were considered as fixed, and pasture plots as random effects. For comparison of the methods applied linear regressions were calculated.

\section{Results and Discussion}

Analysis of variance showed that proportions of botanical components were significantly different in the pasture plots observed

\begin{tabular}{|c|c|c|c|}
\hline & \multicolumn{3}{|c|}{ botanical component } \\
\hline & grasses & legumes & forbs \\
\hline \multicolumn{4}{|l|}{ sources of variance: } \\
\hline methods applied (MA) & ns & $: *$ & ** \\
\hline pasture plots (PPs) & $* *$ & ** & $* *$ \\
\hline dates of observation (DO) & ns & ns & ns \\
\hline \multicolumn{4}{|l|}{ interactions: } \\
\hline $\mathbf{M A} \times \mathbf{P P s}$ & ns & $\star$ & ns \\
\hline MA $\times \mathbf{D O}$ & ns & ns & ns \\
\hline PPs $\times$ DO & ns & $* *$ & ns \\
\hline
\end{tabular}
but did not differ significantly from 1 date of observation to
Table 1. Significant effects at $P \leq 0.05\left(^{*}\right)$ and $P \leq 0.01$ (**) of different sources of variance of the observed variables (botanical components).

ns $=$ non significant

another (Table 1). Significance levels between methods applied depended on the botanical component involved. Since significant effects were found only with methods applied and pasture plots but not with dates of observation, figures for dates of observation are not specified in Table 2 .

There was a trend to underestimate the proportion of forbs and overestimate legumes by the point-intercept methods, whereas the proportion of grasses remained the same no matter which method was applied (Table 2). Forbs, with few and large leaves such as Leontodon hispidus (Del.) Boiss., Echium moschatum (L.) L'Hérit, and Tolpis barbata (L.) Gaertn. may have a relatively high dry matter density within the sward, but because of the low number of leaves, might intercept less frequently with the pins than would be expected by their proportion on a dry matter basis. Numerous small and outstretched leaves of most legumes and grasses increase the chances of pin-contacts, especially because pin diameter is not zero.

In spite of the above-mentioned trends for forbs and legumes, linear correlations over all data between both, specific contribution and percentage cover $(R=0.93 ; P<0.001$; Fig. 1$)$, and percentage of sward and percentage cover $(R=0.92 ; P \leq 0.001)$ were highly significant. The slopes of the regression lines are close to 1 , a

\section{PERCENTAGE CONTRIBUTION}

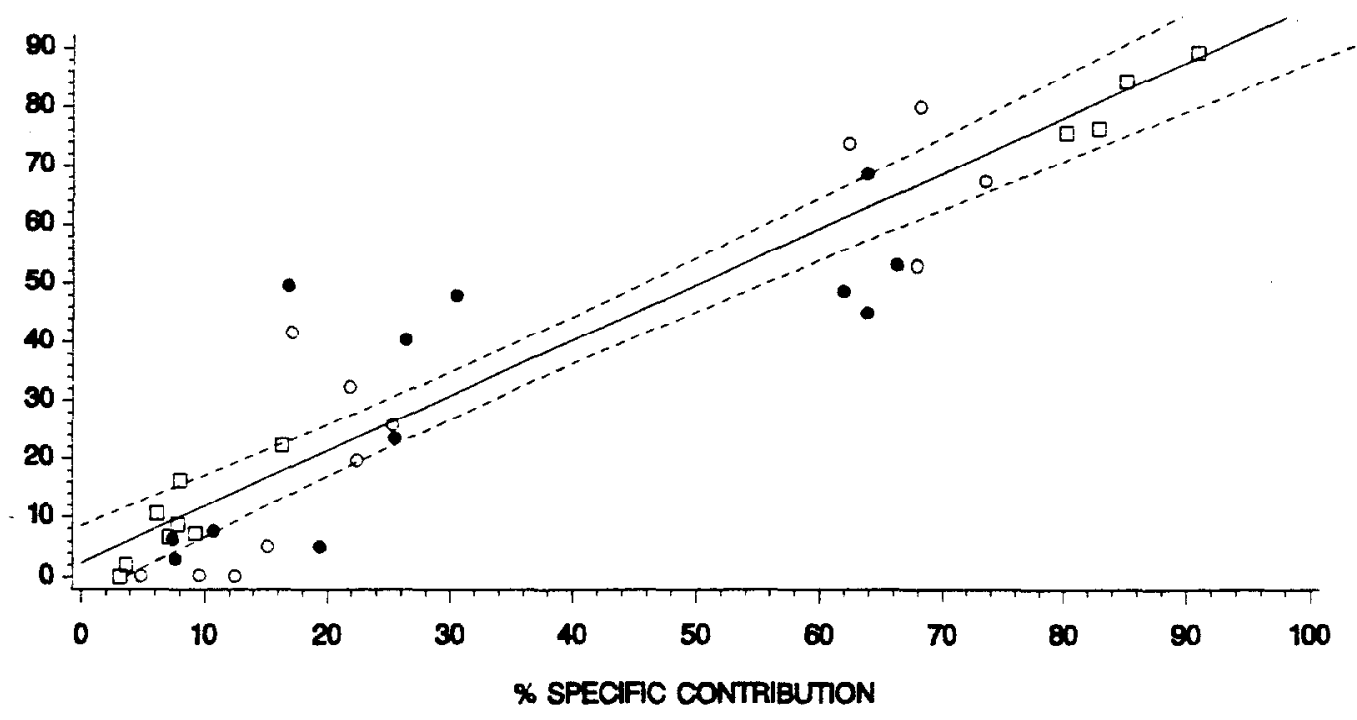

$$
\text { Pasture plots: } \bullet \bullet A \quad \square \square \square B \quad \circ \quad 0 \text { C }
$$

Fig. 1. Linear regression between specific contribution (SC) and percentage contribution (PC) to dry matter yield of botanical components. Confidence intervals at $P \leq 0.05$ are marked.

$P C=0.93 * \mathrm{SC}+2.33(R=0.93 ; P \leq 0.001)$. 


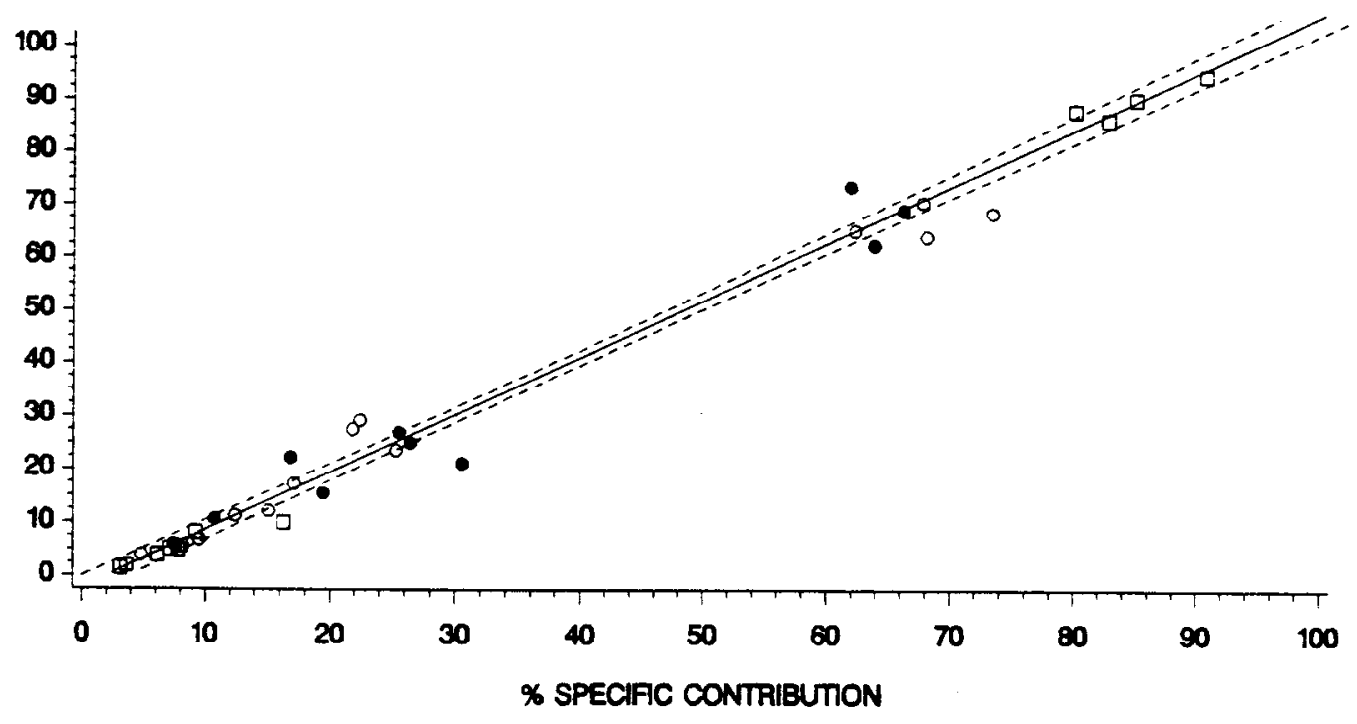

$$
\text { Pasture plots: • - A } \square \text { 口 口 B }
$$

Fig. 2. Linear regression between specific contribution (SC) and percentage of sward (PS) of botanical components. Confidence intervals at $P \leq 0.05$ are marked.

PS $=1.05^{*} \mathrm{SC}-1.98(R=0.99 ; P \leq 0.001)$

Table 2. Means over the four-month observation period of proportions (\%) of botanical components (BC) in the 3 pasture plots observed as determined by 3 different methods (PC = percentage contribution to dry matter yield, $\mathbf{P S}=$ percentage of sward, $\mathrm{SC}=$ specific contribution).

\begin{tabular}{|c|c|c|c|c|c|}
\hline \multirow[b]{2}{*}{ BC } & \multirow[b]{2}{*}{ Method } & \multicolumn{3}{|c|}{ pasture plots } & \multirow[b]{2}{*}{ Mean } \\
\hline & & A & B & C & \\
\hline grasses & $\begin{array}{c}\text { PC } \\
\text { PS } \\
\text { SC } \\
\text { (LSD5) }\end{array}$ & $\begin{array}{l}54.0 \\
66.8 \\
63.9\end{array}$ & $\begin{array}{l}-1 .- \\
81.5 \\
89.7 \\
84.7\end{array}$ & $\begin{array}{l}\%)-- \\
68.6 \\
67.0 \\
67.9\end{array}$ & $\begin{array}{l}78.0 \mathrm{a} \\
74.5 \mathrm{a} \\
72.2 \mathrm{a} \\
(8.9)\end{array}$ \\
\hline legumes & $\begin{array}{c}\text { PC } \\
\text { PS } \\
\text { SC } \\
\text { (LSD5) }\end{array}$ & $\begin{array}{r}5.6 \\
9.4 \\
11.3\end{array}$ & $\begin{array}{l}4.0 \\
4.2 \\
5.8\end{array}$ & $\begin{array}{r}1.5 \\
8.6 \\
10.5\end{array}$ & $\begin{array}{l}3.7 \mathrm{a} \\
7.4 \mathrm{ab} \\
9.2 \mathrm{~b} \\
(4.7)\end{array}$ \\
\hline forbs & $\begin{array}{l}\text { PC } \\
\text { PS } \\
\text { SC } \\
\text { (LSD5) }\end{array}$ & $\begin{array}{l}40.5 \\
23.8 \\
24.8\end{array}$ & $\begin{array}{r}14.5 \\
6.2 \\
9.6\end{array}$ & $\begin{array}{l}29.9 \\
24.4 \\
21.7\end{array}$ & $\begin{array}{l}28.3 \mathrm{a} \\
18.1 \mathrm{~b} \\
18.7 \mathrm{~b} \\
(7.9)\end{array}$ \\
\hline
\end{tabular}

LSDS = least significant difference at $P \leq 0.05$.

result similar to that obtained by Daget et Poissonet (1971) for specific contribution.

Differences between percentage of sward and specific contribution were never significant within any botanical component (Table 2). This may be a result of the factor that sward height was kept low by sheep grazing during the entire observation period. Multiple pin-plant intercepts were relatively infrequent (average of 1.8, 1.2, and 1.2 intercepts per pin contacted by grasses, legumes, and forbs, respectively). Thus differences between percentage of sward and specific contribution remained small.

The correlation coefficient between specific contribution and percentage of sward was very high $(R=0.99, P \leq 0.001$; Fig. 2$)$. It is assumed, that this coefficient declines as average sward height increases. Tall species will intercept more frequently with a pin than low ones of the same sward and, tend to be underestimated by the method determining specific contribution which does not take into account multiple contacts.

Significant differences in the botanical composition (Tables 1 and 2) of the pasture plots may be attributed mainly to differences in managerial history. Regressions between different methods applied were not affected to any significant extent by the pasture plots studied. For legumes only, there was a significant interaction between methods and pasture plots (Table 1). This may have been an accidental effect since legume content of pastures was small and variable.

The procedure of estimating a dependent variable, difficult or expensive to measure, from an independent variable, easy or cheap to measure, on the basis of a regression analysis previously carried out, has been described by Cook and Stubbendieck (1986) as the "double" sampling technique. The regressions reported here were obtained from grazed Mediterranean grassland. They may not readily be extendable to other types of grasslands with different sward height and composition. Revalidation of the above mentioned regressions may be necessary using the double sampling technique.

\section{Conclusion}

Both percentage of sward and specific contribution gave satisfactory estimates of percentage contribution to dry matter yield on continuously grazed annual Mediterranean grassland. There was, however, a significant trend to underestimate forbs and overestimate legumes.

It is suggested that the least laborious method viz. that for determining specific contribution is sufficiently accurate for most cascs of botanical analysis of annual Mediterrancan grassland. It must be kept in mind that species or groups of species may be systematically over or underestimated, especially when swards are heterogenously composed and species differ in leafiness, bulk density in the sward, and growing height. 


\section{Literature Cited}

Cook, C.W., and J. Stubbendieck. 1986. Range research: Basic problems and techniques. Soc. Range Manage., Denver.

Daget, P. et J. Poissonet. 1971. Une Méthode d'Analyse Phytologique des Prairies. Ann. Agron. 22:5-41.

Frame, J. 1981. Herbage mass. p. 39-69. In: J. Hodgson, R.D. Baker, A. Davies, A.S. Laidlaw, and J.D. Leaver (eds.), Sward measurement handbook. The Brit. Grassl. Soc., Hurley.

Glatzle, A. 1990. Weidewirtschaft in den Tropen und Subtropen. Eugen Ulmer, Stuttgart.

Goodall, D.W. 1952. Some considerations in the use of point quadrats for the analysis of vegetation. Aust. J. Sci. Res. 5, 1-41.
Goodall, D.W. 1953. Point quadrat methods for the analysis of vegetation. Aust. J. Bot. 1, 457-461,

Heady, H.F., and L. Rader. 1958. Modifications of the point frame. J. Range Manage. 11:95-96.

Levy, E.B., and E.A. Madden. 1933. The point method for pasture analysis. N.Z.J. Agr. 46:267-275.

Marañon, T. 1988. Agro-sylvo-pastoral systems in the Iberian Peninsula: Dehesas and Motados. Rangelands 10:255-258.

Mueller-Dombois, D., and H. Ellenberg. 1974. Aims and methods of vegetation ecology. Iohn Wiley \& Sons, N.Y.

Taha, F.K., H.G. Fisser, and R.E. Ries. 1985. A modified 100-point frame for vegetation inventory. J. Range Manage. 36:124-125. 